\title{
Sobre bibliotecas, memória e poder
}

Maria Lucia Montes ${ }^{1}$

\section{Resumo}

O artigo explora o impacto das tecnologias da informação e da comunicação na preservação do conhecimento e da memória, uma função tradicionalmente atribuída às bibliotecas após a invenção da escrita. Compara o alcance e a flexibilidade das novas mídias com a tradição oral dos poetas Grécia arcaica e dos griôs africanos enquanto guardiões da memória e da história do seu povo, suas diferenças e similaridades ao tratar sobre a reflexão da produção do conhecimento e da memória, e das relações de poder que a sustenta. Apesar dos resultados imprevisíveis, dado os processos sociais que podem ser desencadeados, a democratização do acesso à informação e à comunicação provenientes das novas mídias é claramente um sinal e um instrumento de mudança na sociedade contemporânea.

Palavras-chave: Bibliotecas. Escrita. Memória. Conhecimento. Tradição oral.

\section{On libraries, memory and power}

The essay explores the impact of technologies of information and communication on the preservation of knowledge and memory, a function traditionally attributed to libraries after the invention of writing. By comparing the range and flexibility of the new media to the oral traditions of early Greek poets or African griots as guardians of the memory and history of their people, it points out similarities that lead to reflect on the very production of knowledge and memory, and the power relations supporting them. However unpredictable its results, given the open-ended social processes it can trigger off, the democratization of access to information and communication provided by the new media is clearly a sign and an instrument of change in contemporary societies.

Key words: Libraries. Knowledge. Memory. 
Bibliotecas são coleções estranhas, porque têm por objeto, sob as mais variadas formas e nos mais diversos suportes, o que se pretende devam ser. repositórios do conhecimento humano! Seriam tão só coleções de palavras, gravadas sobre esses suportes, a nos mostrar alguma parte de um tão vasto universo? Palavras escritas onde se espelham inquietudes, sonhos, o empenho em busca da verdade, a exploração de relações humanas, do mundo natural e dos deuses, mentiras construídas com esmero, laboriosas descobertas talvez refutadas depois, instantes flagrados da eterna tentativa do homem de compreender a si mesmo e ao mundo que o cerca... Palavras de poder, portanto, pois fixadas para resistir e permanecer, para além da voragem do tempo que tudo arrasta atrás de si.

Por certo, bibliotecas também guardam compêndios de arte como expressão do conhecimento humano, traduzida em imagens de obras que reproduzem ou ao menos buscam sugerir suas formas e suas cores, seus materiais e suas texturas. Não fosse isso - a diferença entre a coisa e seu duplo imagético - bibliotecas não seriam muito distintas de museus de arte - ou, na verdade, de quaisquer museus já que têm, como eles, a mesma contraditória missão de, há um tempo, salvaguardar e permitir o acesso, conservar e expor, preservar para melhor divulgar e difundir. Custodiar e gerir a relação dos homens com objetos de memória reputados de valor, e que constituem o conhecimento. Educar para que este valor seja reconhecido e incorporado como patrimônio comum da humanidade. Uma tarefa de poder, portanto, que seleciona, às vezes por obra do acaso, o que esquecer ou lembrar, ao menos enquanto possam durar os efêmeros suportes da memória.

Contudo, dependeriam unicamente desses suportes a preservação dos conteúdos da memória e a transmissão do conhecimento que carregam? Convencionalmente, bibliotecas nos remetem ao universo da palavra destinada a se tornar pública ao ser resgatada, depois, ao menos por um outro distinto daquele que a enunciou, uma vez inscrita no papiro, desenhada no pergaminho, impressa no papel. Bibliotecas nos falam do mundo dos livros, em suma, embora possam comportar também o documento, a carta de amor ou a sentença de morte, a publicação periódica ou o panfleto ocasional. No entanto, as tecnologias da informação e da comunicação não 
estão hoje a nos ensinar que esses suportes convencionais de preservação e acesso ao conhecimento podem se tornar perfeitamente obsoletos, sem que a matéria viva do conhecimento se perca? Flutuando no meio imaterial de um cyberspace, abrigado de forma invisível em entidades chamadas bytes, bits, algoritmos e outros nomes misteriosos - combinatórias e equações matemáticas, regras de operação e sistemas de símbolos gerenciados em programas de processamento, armazenagem e manipulação de informações que podem ser disponibilizadas de maneira instantânea sobre a tela de um computador, um i-Pad, um celular - não é ainda do mesmo patrimônio do conhecimento humano que se trata?

A existência dessas modernas tecnologias nos obriga a pensar as bibliotecas de outra perspectiva, voltando quase a um tempo de origem para refletir sobre 0 conhecimento, sua guarda e seu acesso. Na sociedade em que vivemos, tornam-se irrelevantes as diferenças entre os suportes ou mesmo as matérias do conhecimento que se organiza e se veicula por meio de suas poderosas ferramentas tecnológicas. Por que associar as bibliotecas a coleções de livros e à palavra como meio de conservação do conhecimento, quando pode haver outros modos de reunir em coleção e armazenar bancos de imagens, arquivos de sons, gráficos e formas em movimento, expressões de outras tantas formas do conhecimento humano, igualmente disponibilizadas e acessíveis a um simples toque nesse novo mundo virtual?

Reduzidos à categoria de informação e meio de comunicação, todas essas formas de conhecimento e seus suportes materiais, que julgávamos necessário classificar para melhor distinguí-los e manejá-los, se revelam como sendo apenas sistemas codificados de signos, linguagens destinadas a produzir uma mensagem e tornar possível a sua comunicação. É a questão da codificação que nos alerta para uma característica intrínseca à sua natureza, quando vistos sob essa perspectiva semiótica: em todas as suas expressões, constituem alguma forma de escrita, o que supõe a existência de um código para sua inscrição e o conhecimento dele para tornar possível a leitura. Teria essa condição necessária de acesso ao conhecimento sob a égide das tecnologias da informação e comunicação também alguma influência sobre o próprio modo de produção do conhecimento, seu lugar e 
significado no mundo contemporâneo? Que relações de poder aí estão em jogo, reforçando ou desestabilizando velhas regras de domínio que sempre marcaram uma indisfarçável presença no território do conhecimento?

É preciso voltar no tempo para melhor refletir sobre esta questão. Primeiro, foram os desenhos nas paredes das cavernas. Depois, signos gravados em pequenas placas cerâmicas para comunicar um pedido aos deuses, um decreto real, um contrato. Só mais tarde o papiro, o pergaminho ou o papel viriam a acolhê-los. A invenção do alfabeto e da escrita desprendeu o conhecimento das interações face a face entre os homens e permitiu sua acumulação e armazenagem sem a dependência da memória, ao mesmo tempo em que sua transmissão foi liberada da necessidade de uma forma direta de comunicação humana². Foi para a custódia e gerenciamento de todo esse imenso universo do conhecimento codificado em escritura que se criaram as bibliotecas, desde Alexandria.

Entretanto, sociedades inteiras ao longo da história confiaram à oralidade a guarda e a transmissão do conhecimento ou, pelo menos, daquele conhecimento considerado mais relevante e essencial para a sua própria sobrevivência e a de seus membros. $\mathrm{Na}$ Grécia arcaica, cabia esta tarefa aos mnemones e aos aedos, a exemplo de Homero e Hesíodo, que cantavam em seus versos, inspirados pelas Musas filhas da Memória, os deuses e os heróis do passado, assim como os trabalhos e os dias no presente dos homens e o seu destino futuro. Em muitos países africanos, era um mestre griô que detinha com exclusividade essa função, em razão de pertencer a uma linhagem que desde tempos imemoriais a exercera, sendo, portanto, capaz de transmitir-lhe a competência técnica necessária ao seu desempenho.

Poeta, músico, compositor, historiador, conselheiro real, porta-voz, diplomata, emissário de paz, intérprete, tradutor, professor, um mestre griô sempre foi uma personificação viva da história, das tradições e dos valores da cultura de seu povo, e os difundia por intermédio das grandes sagas, como a do rei Sundiata, tão importante para a cultura do Mali quanto o Mahabarata para a Índia ou a saga dos Niebelungen para a Alemanha. Entretanto, em cada aldeia e vilarejo aonde chegasse ele narraria não a saga inteira, mas algum episódio dela que mais se aproximasse da realidade daquele pequeno mundo. Adaptava assim a história 
narrada à audiência e às circunstâncias do momento, permitindo que ela fosse apropriada por cada um e dando a cada um o sentido de pertencimento à história maior de todo o seu povo ${ }^{3}$. Ainda hoje há mestres griôs capazes de cantar essas sagas, acompanhando sua narrativa do som de instrumentos musicais tradicionais que sempre foram essenciais à preservação do prodigioso patrimônio de sua própria memória. Assim, quando morre um deles, dizem os historiadores africanos, é como se toda uma biblioteca fosse queimada e desaparecesse com ele...

O que podemos aprender nesse universo dos mestres griôs que nos ensine algo sobre nosso próprio mundo e as formas de custódia e acesso ao conhecimento que ele torna possíveis?

Apesar da célebre advertência de Platão, no Fedro, sobre os efeitos nocivos da escrita - que seria não um auxiliar da memória, mas um instrumento de sua perda, uma vez confiada a guarda do conhecimento a algo exterior ao homem, e não mais à sua capacidade de "rememorar" a verdadeira natureza das coisas no mundo das formas, como ensina a filosofia, e de transmitir e compartilhar esse conhecimento, na interação do diálogo, como uma experiência vivida ${ }^{4}$ - o fato é que aquela invenção atribuída por Sócrates à divindade egípcia Thoth, e que os próprios gregos associavam a Hermes, o deus mensageiro, teve consequências irreversíveis, e foi de decisiva importância para os rumos do Ocidente que se tornaria herdeiro da civilização greco-romana. Dessa invenção nasceriam as bibliotecas, cujo perfil iria variar ao longo da história na medida em que variaram os suportes do conhecimento a que elas dão abrigo. Na forma física de seus objetos - textos feitos de palavras às vezes ilustradas por imagens - as coleções ali armazenadas guardam os traços dos diferentes artefatos em que sua escrita foi registrada. $O$ codex conservou as colunas do rolo de pergaminho, e o livro impresso, a página do codex. Todavia, hoje, a escrita virtual que as tecnologias de informação e comunicação tornam possível nos oferece mais que o livro eletrônico, que retoma a página do livro impresso como seu modelo de comunicação com o leitor ${ }^{5}$.

Perdendo sua soberania, a palavra deve agora partilhar o espaço de uma tela de luz com outras formas de representação do conhecimento em meio digital, convivendo com outras escritas de imagens, vozes, sons, movimentos que compõem outros 
tantos tipos de textos, visuais, orais, musicais, audiovisuais, tudo acessível em um mesmo espaço, ao alcance instantâneo de um toque, em um único equipamento de transmissão e recepção de informação. Desmaterializado por meio dos seus suportes digitais, o conhecimento se transforma em algo fluido, instável e indefinido, suscetível de uma variação quase infinita de suas expressões. Se, enquanto forma de escritura, esses textos exigem para a compreensão de seu significado a leitura, que decifra o código de sua inscrição, tal como ocorre com a palavra, é inegável que essa leitura envolve agora outro tipo de experiência, polifacetada, pluridimensional, multisensorial, convocando uma variedade de capacidades intelectivas do ser humano para apreender de modo simultâneo e organizar como um todo coerente esse conjunto diversificado de códigos transmissores de informações que bombardeiam o leitor quase que pelos cinco sentidos. Ao lado da inteligência analítica e racional que sempre foi associada ao domínio da palavra, estariam esses novos instrumentos tecnológicos abrindo espaço também a outras habilidades sensoriais e cognitivas do homem, à intuição, à imaginação, até mesmo à sensibilidade estética, como condição de recepção e acesso ao conhecimento? Pois não é essa capacidade de apreensão sintética que é necessária quando a palavra se associa à música, à imagem, à animação das formas, que agora constituem os textos em que também se pode armazenar e preservar 0 conhecimento? ${ }^{6}$

E o que dizer da possibilidade da leitura aleatória e não sequencial de todos esses textos, integrados como um único texto, hipertexto que se esparrama em múltiplas direções, ramificações de uma nova árvore do conhecimento, e que facultam ao leitor escolher seus próprios caminhos de acesso, numa tela interativa? Aí estão os links que tornam possível, a partir de um tema inicial qualquer, a exploração de toda a vasta gama de suas conexões, permitindo a passagem de uma informação a outra, dentro de um mesmo território conceitual ou em campos diferenciados do conhecimento, e de uma linguagem à outra, em termos dos suportes digitalizados que são ligados por uma programação anterior em um sistema telemático, aberto a um escrutínio ilimitado. Então, aqui já não mais estamos apenas no domínio do acesso ao patrimônio do conhecimento humano, mas no de sua própria produção. Pela liberdade que os novos meios técnicos oferecem à leitura, o leitor se torna produtor do conhecimento, ou ao menos seu coautor, à medida que o acessa. Para 
o bem ou para o mal - e isso só o tempo dirá - ele escapa ao controle dos que disponibilizavam o conhecimento na forma de livro ou de qualquer outro tipo de impresso, que já pela sua forma material condenava o leitor a percorrer as páginas encadernadas em sequência fixa, ordenadas pela autoridade da palavra do autor, o arbítrio do editor ao escolher publicar ou não um livro, e mesmo o poder daqueles que, nas bibliotecas, se responsabilizam pela classificação e organização do conhecimento enfeixado nos seus livros ou documentos, bem como pela distribuição dos volumes impressos nos espaços de sua conservação e acesso, arquivos catalográficos, salas de leitura ou setor de empréstimos e circulação.

O que está em jogo nesse processo é uma profunda transformação da relação do homem com o conhecimento por ele acumulado no espaço e ao longo de um tempo que se mede por milênios. Tanto no que se refere às ferramentas tecnológicas e aos processos técnicos envolvidos na produção, organização, conservação e acesso ao conhecimento quanto em termos das relações sociais que eles pressupõem e viabilizam, assistimos à desestruturação de um modelo milenar e sacrossanto de custódia do conhecimento, progressivamente desafiado por algo novo, que consiste na sua conservação e distribuição em redes que funcionam em escala global. Na era da informação e da comunicação, em que o conhecimento pode ser transmitido e apreendido sob a forma nova dos hipertextos, há que entendê-los como instrumentos de uma mudança crucial. Hipertextos são textos que trazem conexões com outros textos que, por sua vez, se conectam a outros, formando uma grande rede de textos. E esta rede se estende por outras redes progressivamente ampliadas de ferramentas que a ela dão acesso, até se chegar à rede mundial www (World Wide Web) ou esta espécie de rede das redes que é a internet. As trocas em escala planetária que se tornam possíveis graças a esses navegadores que possibilitam a manipulação direta da informação pelos usuários permitem simultaneamente inventar novas estratégias para a própria produção do conhecimento.

De fato, nesse contexto, escrita e leitura como forma de conservação e acesso ao conhecimento deixam de ser habilidades técnicas e funcionais a serem aprendidas para se transformarem em processos sociais em permanente transformação e atualização. $O$ texto já não será mais visto como uma sequência de palavras ou 
outros sistemas de signos codificados em escrita, mas sim como resultado de um sistema de ações comunicativas, um evento no qual convergem ações linguísticas, cognitivas e sociais para a construção do seu significado ${ }^{7}$. A pluralidade e a heterogeneidade dos elementos que assim se conectam como construção em sistema e se difundem como comunicação em rede - palavras, sons, imagens, enunciados em múltiplas linguagens, mas também atores sociais, participantes da rede, contextos em que desenvolvem suas ações - fazem do texto um evento interativo e não um simples artefato, um processo e uma coprodução envolvendo multissistemas de signos, cujos elementos precisam ser compreendidos em suas características multifuncionais ${ }^{8}$.

Aqui se detectam pontos de ruptura que são fundamentais ${ }^{9}$. A interatividade na produção e no acesso ao conhecimento, a manipulação da informação que ela faculta a todos e a cada um, a possibilidade de correlacionar entre si as mais diferentes formas e expressões do conhecimento por meio de links e sua extensão em nós de redes hipertextuais introduzem a pluralidade e a diferença, a descontinuidade e a simultaneidade no universo do conhecimento como uma característica essencial que já não mais será possível descartar. A intervenção do leitor que agora invade sem cerimônia o texto, sem precisar recorrer à velha anotação à margem da página, dissolve as fronteiras que nos separavam, enquanto leitores, dos autores que, por meio dos livros, nos eram mostrados como responsáveis pela produção do conhecimento. Agora somos todos responsáveis, individual e coletivamente, por essa produção graças às ferramentas tecnológicas que lhe dão acesso, e que permitem sua divulgação segundo o interesse e sob a responsabilidade de cada um. Esta é uma revolução em termos das relações de poder que sempre sustentaram a produção e o acesso ao conhecimento. Nesse universo, já não é possível manter a ficção de uma "grande narrativa", um discurso unívoco em torno de algum princípio fundamental a explicar o andamento das coisas do mundo, nem a ideia de uma objetividade do conhecimento, que sempre orientou a busca de verdades definitivas, substituídas agora pela irrefutável experiência de sua relatividade.

Dessa perspectiva, a escrita no mundo contemporâneo - ou, melhor diríamos, as escrituras diversificadas às quais ela cede o lugar - bem como os seus suportes 
materiais e as ferramentas tecnológicas de sua produção e acesso, podem ser entendidos, como propõe Mikhail Bakhtin, enquanto gêneros discursivos que traduzem formas específicas do uso da língua e da criação de textos numa dada época ${ }^{10}$. Compreendida enquanto fenômeno social, a própria linguagem revela como sua característica a pluralidade e a heterogeneidade e recusa qualquer abordagem que se pretendesse basear em classificações e hierarquias entre os gêneros discursivos. Como a linguagem, o próprio texto não é senão uma tessitura de redes de relações sociais envolvendo ferramentas tecnológicas que medeiam sua construção, e cujo resultado é a produção do sentido provocado por ele entre os interlocutores que participam desse processo.

Ainda que esta possa parecer uma descoberta relativa a um fenômeno exclusivamente contemporâneo, de fato ela retoma a visão de uma antropologia interpretativa que, entendendo a cultura como criação característica do gênero humano, a define, na formulação de Clifford Geertz, como conjunto de textos que desde sempre os homens inscrevem no mundo por meio de suas ações e cujo significado tentamos decifrar por sobre os seus ombros, no próprio ato de sua escrita. O homem, diz Geertz, é um animal enredado em teias de significados que ele próprio constrói ${ }^{11}$. Nesse sentido, Bakhtin apenas retorna a esse veio, de inspiração fenomenológica e hermenêutica, ao compreender a escrita e suas transformações históricas como um gênero discursivo que se constitui pela expansão e pelo redimensionamento dos suportes materiais e tecnológicos da cultura. O mundo contemporâneo apenas evidencia com mais clareza esse fenômeno ao exacerbar a relação entre ferramentas de construção e difusão do conhecimento e a construção social dos significados no plano da cultura, levando-a as últimas consequências. Eis o que, nos anos 60 do século passado, nos dizia de maneira revolucionária Marshall Mc Luhan, ao afirmar que "o meio é a mensagem". A partir de então se reconhecia que os hipertextos, as redes e os suportes digitais propiciados pela invenção das novas tecnologias da informação e da comunicação haviam se tornado as ferramentas por excelência por meio das quais a humanidade iria gerenciar o conhecimento, gerar e dar acesso à informação, interpretar a realidade e transformá-la ${ }^{12}$. 
E não é isso que nos mostram as redes sociais como o Facebook e o Twitter no seu impacto sobre processos de transformação de ordem global como a chamada "primavera árabe", responsável pela queda de governos ditatoriais no Oriente Médio? Não é isso o que evidencia o recente movimento de protesto nos Estados Unidos, Occupy Wall Street, que em pouco mais de dois meses se espalhou de forma viral pelo mundo, conclamando à mudança e à justiça, frente ao domínio planetário do capitalismo financeiro que corrói a vida social, destrói o meio ambiente e corrompe os governantes em todos os quadrantes da Terra? Não é a determinação de lutar pelo direito de acesso à informação e ao conhecimento o que levou à criação do Wikileaks e ao escândalo da divulgação de informações de fontes diplomáticas e militares norte americanas, consideradas secretas por envolverem questões de segurança nacional? Como era previsível, a articulação da reação em escala mundial não se fez esperar, levando à tortuosa invenção de um processo contra Julian Assange, criador do Wikileaks, hoje mantido em prisão domiciliar na Inglaterra, ou, de forma mais grave, à prisão de Bradley Manning, jovem militar americano considerado responsável pelo vazamento daquelas informações e hoje mantido preso, à espera de uma corte marcial, em condições consideradas como tortura por organizações internacionais de defesa dos direitos humanos.

Nada disso é de estranhar. O segredo e a custódia rígida da informação e do conhecimento sempre foram os grandes aliados do poder, e não será sem um vale tudo do qual foi excluída qualquer barreira ética que os seus detentores no mundo de hoje estarão dispostos a entregá-lo. A mais recente batalha se configurou - e não por acaso - na tentativa de controle da internet sob pretexto de combate à pirataria digital, pela violação dos direitos autorais das grandes empresas americanas da indústria do entretenimento, produtoras de filmes e músicas divulgados pela internet em sites e portais no exterior. Vistos em sua indisfarçável intenção de censura, dois projetos de lei em tramitação no Senado e na Câmara Federal dos Estados Unidos, que visariam a impedir esse tipo de fraude, desencadearam nos grandes sites de busca e de compartilhamento de informação, como a Wikipaedia e o Megaupload, uma fantástica reação. Juntando-se a abaixo assinados, telefonemas, e-mails e outras formas de pressão de alguns milhões de usuários, os sites "piratas" voluntariamente saíram do ar ou bloquearam parcialmente seu acesso, aumentando a grita de protesto, ao mesmo tempo em um grupo de hackers conhecido como 
Anonymous invadia o sistema de segurança e derrubava os sites do Departamento de Justiça, do $\mathrm{FBI}$ e de outras instituições de governo nos Estados Unidos... Por enquanto estão vencendo os internautas norte-americanos e de todo mundo, cuja pressão fez com que mesmo políticos conservadores, que haviam contribuído com a redação dos projetos, mudassem de idéia e retirassem o apoio que thes haviam dado de início. Mas essa batalha vem tendo novos e surpreendentes desdobramentos e ainda está longe o seu fim.

Entretanto, deixando de lado os jornais do dia, já é tempo de voltarmos aos mestres griôs que anteriormente invocamos e que nos ajudam a entender em parte o que está em jogo nessa guerra em pleno curso. Não se parece estranhamente com o modo griô de lidar com o conhecimento a linguagem multimídia com que as tecnologias de informação e comunicação hoje o produzem, conservam e the dão acesso? O elemento lúdico envolvido na performance de um mestre griô - suas ferramentas de transmissão do conhecimento, a poesia e a música, ou sua liberdade de escolha dos episódios de uma saga heróica a ser contada em diferentes vilarejos - não apresenta semelhança com o gosto pela liberdade de multiplicar as linguagens e os suportes na leitura de um hipertexto e o prazer de brincar com os pequenos jogos que as tecnologias contemporâneas põem à disposição de todos, nos mais variados aparelhos e equipamentos, do computador ao celular? As múltiplas funções de um mestre griô - artista, historiador, conselheiro político, embaixador, tradutor, professor, entre outras - não se assemelham àquelas que cada um pôde assumir, alternada ou simultaneamente, ao se envolver em movimentos sociais e políticos que exigem organização para o cumprimento de diferentes tarefas, como logística, comunicação, planejamento etc., e que contaram com apoio e divulgação pela internet? As estratégias de interação que hoje permitem a produção coletiva do conhecimento e a mobilização para a ação pela mídia digital não têm também uma dimensão lúdica capaz de transformar a função social que as define como forma de trabalho, já que, como afirma o filósofo Villem Flusser, são os instrumentos técnicos que emancipam o homem do trabalho, libertando-o para o jogo ${ }^{13}$

Essa coexistência entre trabalho e gratuidade lúdica esteve presente na Praça Tahir, no Cairo, ocupada pelo povo que, entre a repressão policial e as tarefas de 
organização, encontrava tempo para criar o canto de protesto logo espalhado pela multidão. E esse movimento se repete nos acampamentos do Occupy Wall Street, em Nova York, e outras cidades americanas, inclusive com a invenção do mic check, o microfone humano que permite a repetição da palavra de um por todos, garantindo a transmissão da mensagem, ao mesmo tempo individual e coletiva. Por certo, a função primordial de um mestre griô sempre foi a preservação das tradições e valores de seu povo, de modo a infundir um sentido de pertencimento de cada membro de um vilarejo à comunidade maior de seu grupo étnico e sua história. E, hoje, é isso o que reencontramos nos movimentos de protesto libertário em todo o mundo, difundindo um mesmo sentimento de unidade e solidariedade na aldeia global em que vivemos. Mas seria suficiente esta convergência de meios e fins para estabelecer uma comum medida que nos permitisse falar, nos mesmos termos, de um vilarejo africano e de nossas metrópoles cosmopolitas? Não haveria uma mudança significativa nesses processos de comunicação e divulgação da informação e do conhecimento em função de sua escala?

O que é notável nesses processos, quando mediados por nossas modernas tecnologias, é que eles põem em cena, irrevogavelmente, a heterogeneidade e a pluralidade, a diferença e a igualdade, permitindo passar sem solução de continuidade de questões de interesse puramente local a outras de alcance mundial. Se as redes sociais como o Facebook e o Twitter são essencialmente instrumentos de compartilhamento de fragmentos de experiências pessoais e individuais de interesse restrito a uma comunidade de amigos e seguidores, elas também demonstraram ser, de forma inequívoca, poderosas ferramentas de mobilização política em escala planetária. Entre esses pólos aparentemente contraditórios, o que está em jogo é a dialética sutil de uma identidade que traduz um pertencimento local ao mesmo tempo em que se afirma como parte de uma comunidade mais ampla, e que intuitivamente entendemos, em versão prosaica mais próxima de nós, quando um puxador de samba-enredo a invoca com seu "grito de guerra" ao entrar na avenida: "Olha a nação Beija-Flor aí, minha gente!" O movimento constante entre o local e o global, e a incerteza necessária quanto aos resultados dos processos assim desencadeados, em razão de seu caráter aberto e sempre indefinível por antecipação, são talvez o melhor retrato da nossa sociedade atual, e também seu grande desafio em vista da construção de um novo modelo de democracia e de 
liberdade a que hoje parecem aspirar todos os povos. E tudo isso está inextricavelmente ligado à era da informação e da comunicação e às novas ferramentas tecnológicas que hoje comandam a produção e o acesso ao conhecimento.

Por esse caminho podemos voltar às bibliotecas, nosso ponto de partida. Como instituições que são ferramentas de salvaguarda, conservação e acesso ao patrimônio do conhecimento humano, elas não poderiam deixar de refletir esse movimento mais amplo da sociedade contemporânea. Sua tarefa de custódia e controle do acesso ao conhecimento se vê abalada pela transformação radical das relações sociais e de poder que historicamente a sustentaram. Entre as funções contraditórias de preservar e permitir o acesso ao conhecimento que sempre lhes incumbiu, cada vez mais o acesso vai ganhando terreno, exigindo de forma crescente das bibliotecas sua adequação ao novo perfil de instituições prestadoras de serviço, para disponibilizar aos usuários informações que cada vez mais facilitem o seu acesso aos tesouros do conhecimento humano que lhes cabe preservar. É esse processo de democratização crescente da partilha do conhecimento que coloca como questão o direito ao seu acesso para os que dele ainda se vêem excluídos.

Políticas públicas de inclusão social progressivamente têm passado a enfatizar, nas áreas de educação e cultura, a necessidade de ampliação da inclusão digital, pela disponibilização de um número crescente de computadores às escolas ou a instalação, nas áreas mais carentes, de equipamentos públicos como os telecentros. Neles, tal como em centros comunitários e lan houses, torna-se possível aos jovens das periferias das grandes metrópoles iniciarem-se no domínio das linguagens e das ferramentas das novas tecnologias, ao mesmo tempo em que ampliam sua informação e se divertem com os jogos que acrescentam um elemento lúdico à aprendizagem e à aquisição do conhecimento. No Ministério da Cultura, o programa Cultura Viva fez questão de incluir, desde a gestão do ministro Gilberto Gil, estações completas de tecnologia digital de geração e distribuição da informação, permitindo que, do Oiapoque ao Chuí, grupos culturais marginalizados, produtores de manifestações consideradas folclóricas, comunidades indígenas e quilombolas passassem a ter domínio sobre a gestão da produção e divulgação de suas criações 
e de sua própria imagem, por meio de gravações de CDs, DVDs e vídeos documentários por eles mesmos realizados.

É nesse panorama que é preciso situar, nas bibliotecas, o esforço de digitalização de seus acervos, de sua documentação e de disponibilização de serviços de informação aos usuários. As maiores bibliotecas do país hoje se orgulham de se transformar em bibliotecas virtuais, que permitem o contato com o conhecimento que ali se preserva a partir de qualquer ponto onde um leitor possa contar com tecnologias e equipamentos de acesso para consultá-las on-line. Ao lado disso, há que acrescentar a questão da acessibilidade. Hoje, nas bibliotecas, assim como nos museus, tornou-se obrigatória a presença de facilitadores de acesso aos seus espaços e seus acervos a portadores de deficiência que antes se viam impedidos de frequentá-los. Rampas de acesso, instalações internas adaptadas e equipamentos auxiliares de mobilidade, como cadeiras de roda ou pequenos scooters eletroeletrônicos, cada vez mais se encontram disponíveis aos portadores de deficiência física. $E$ aos poucos também já vem se tornando rotina a presença de livros em Braille e áudio books nas bibliotecas, em benefício dos portadores de deficiência visual e auditiva. A contratação de tradutores de Libras começa a ser incluída no planejamento e organização de eventos como conferências, palestras e seminários nas bibliotecas, assim como acervos que podem ser manipulados e etiquetas de obras em Braille passam a ser uma exigência do trabalho educativo nos museus. A acessibilidade vem se tornando mais um item obrigatório nos projetos de reforma ou instalação de novas bibliotecas e museus.

Cabe, pois, dessa perspectiva, retomar enfim a questão da função de preservação da memória que sempre incumbiu às bibliotecas e aos museus, indagando sobre o impacto que a democratização do acesso ao conhecimento veio a exercer sobre os procedimentos técnicos a ela relacionados e até mesmo sobre a concepção dessas instituições como guardiãs de memória. Se os mestres griôs tinham a responsabilidade de guardar em sua memória individual a história de seu povo, e às bibliotecas tradicionais cabia a função de custodiar e permitir o acesso ao patrimônio do conhecimento de toda a humanidade, como memória preservada nos registros de seus livros e documentos, hoje as tecnologias da informação e da comunicação 
permitem delegar a um coletivo essa tarefa, embaralhando, de modo paradoxal, as fronteiras entre o passado e o presente e entre memória e história.

Da sua preservação dependente da subjetividade de um único narrador, o mestre griô, a memória coletiva agora se amplia, sustentada por redes digitalizadas que congregam milhares de vozes e olhares, e nas quais a história vai sendo escrita, narrada, comentada e registrada em tempo real, dia a dia, byte a byte, escancarando essa informação em regime universal de acesso ${ }^{14}$. A capacidade de que sempre dispuseram bibliotecas e museus de escolher, ao sabor das vicissitudes da história, o que seria preservado como memória ou relegado ao desconhecimento e ao olvido, agora se dilui por entre os milhões de usuários das tecnologias de informação e comunicação, de cujas interações dependerá a permanência ou não de um evento da história em um registro de memória. Assim, o poder que se ocultava por trás da construção, no presente, da memória do passado, agora põe a nu sua falácia e sua pretensão de universalidade, evidenciado seu caráter ao mesmo tempo arbitrário e nada inocente, já que expressa, precisamente, essa condição de poder que estava em sua origem. Todavia, entre as miríades de redes que hoje constroem as narrativas fragmentárias e plurais da história, o que, na voragem do tempo que tudo arrasta atrás de si, será engolido como irrelevante (para quem?) ou preservado como monumento de memória - tal como fazem bibliotecas e museus -, é algo que resta saber e só o tempo poderá dizer.

Entretanto, há já um ganho seguro que é possível apontar em todos esses processos carregados de ambigüidades, contradições e incertezas quanto ao futuro. Ao reduzir, sob a égide da informação, todo conteúdo e toda forma de conhecimento a linguagem de signos codificados - ao risco de dar razão ao velho temor de Platão quanto à sua indistinção - as novas tecnologias da informação e da comunicação permitem, no entanto, tratar todo conhecimento de modo igualitário, ao considerá-lo como conjunto de textos inscritos no tempo e no espaço da história pela ação humana e a dinâmica da cultura. Vendo-os sob a perspectiva não dos códigos de sua enunciação - que pertencem ao plano da vida social mais ampla ou das ferramentas tecnológicas que hoje disponibilizam o seu acesso - mas do evento comunicativo do seu enunciado - ação social de construção de significados no plano da cultura - torna-se possível compreender que de fato não existe distância ou 
oposição entre a oralidade e a escrita enquanto gêneros discursivos ${ }^{15}$. Ao contrário, o que se percebe é a semelhança e a inter-relação entre ambos, marcados pela mesma complexidade e diversidade dos elementos que os constituem, em um como em outro caso. Transitando entre palavras, imagens, sons e movimentos que são signos que constroem significados, tanto a fala quanto a escrita se tornam ferramentas de produção de conhecimento que testemunha o esforço humano de atribuir sentido à sua experiência do mundo. São formas complementares de registro dos acontecimentos, excepcionais ou cotidianos, da vida do homem, de seus sonhos e descobertas, de seus medos e esperanças. Ou, dito de outro modo, registro da linguagem em ação na imensa diversidade de práticas que compõem sua existência, num vilarejo africano assim como na aldeia global.

Por isso é preciso concluir que o mestre griô não teve sua função superada por conta da invenção da escrita e das bibliotecas, nem os livros e as bibliotecas se tornarão desnecessários frente aos novos suportes e ferramentas tecnológicos de construção e acesso ao conhecimento na era da informação digital. Em nosso mundo contemporâneo, dominado por essas tecnologias de informação e comunicação, talvez o fascínio que elas exercem seja o de permitir vislumbrar, numa ainda desconhecida biblioteca do futuro, a possibilidade de recuperar de algum modo - na comunicação direta, imediata e personalizada que se dá nas redes organizadas em torno de interesses comuns - algo como um equivalente da oralidade responsável pela construção do saber dos mestres griôs e, quem sabe, talvez recuperar também algo de sua sabedoria. Utopia, talvez, mas que traduz uma esperança de se resgatar o conhecimento como construção humana coletiva e seu acesso como prática de trocas, diálogo aberto e infindável que nos devolve, como bem sabiam Sócrates e os mestres griôs, o seu verdadeiro sentido de experiência compartilhada e de pertencimento, não a um grupo ou uma sociedade, mas à humanidade e à trama da vida, em nossa casa comum, a Terra que habitamos. Só o tempo dirá se, no mundo atual, isto é ainda possível. 


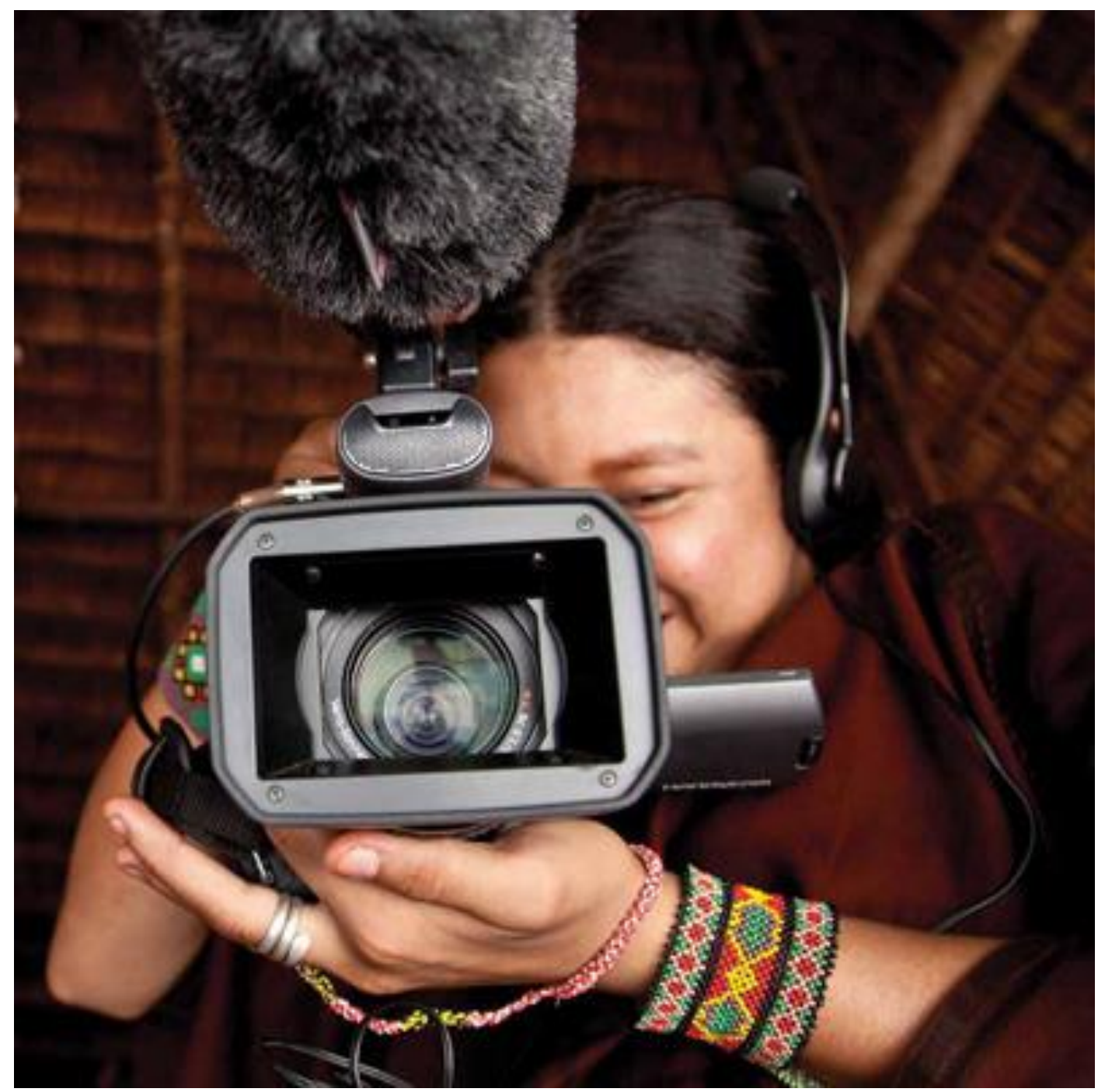

Figura 1

\section{Notas}

(1) Bacharel em Filosofia pela USP, iniciando depois um Doctorat de 3e. cycle na França, que não chegou a concluir. Mestre em Sociologia na Universidade de Essex, Inglaterra. Doutora pelo Departamento de Ciência Política da USP. Integrou o Departamento de Antropologia da USP até aposentar-se. Dedica-se a projetos culturais, museus, exposições, edição de catálogos e livros de arte.

(2) Rita de C. R. A informação escrita: do manuscrito ao texto virtual. In: Informação, conhecimento e sociedade digital. VI Cinform - Encontro Nacional de Ciências da Informação. Salvador, 14-17 jun 2005. Disponível em: < http://www.cinform.ufba.br/vi_anais/docs/RitaQueiroz.pdf>. Acesso em: 7 jan. 2012. Cf. também: LE GOFF, J. História e memória. 4.ed. Campinas: UNICAMP, 1996.

(3) Na monumental publicação da Unesco, dos oito volumes da História Geral da África, o primeiro deles trata em sua longa introdução de questões metodológicas e coloca a oralidade no centro do desafio de escrever a história de sociedades ágrafas. O exemplo do mestre griô é apenas um dos casos, embora central, em que a oralidade, veículo da tradição, é mostrada como essencial à compreensão de cada instituição e de cada 
atividade nas sociedades do continente. Cf., em especial, os cap.7 e 8 dessa introdução: VANSINA, J. A tradição oral e sua metodologia; Hampaté Ba, A. A tradição viva. In: UNESCO. História geral da África, v. I. Metodologia e Pré-História. UNESCO, 2009 (tradução em português).

(4) PLATÃO. Diálogos. Mênon. Banquete. Fedro. Tradução do grego pelo Dr. Jorge Paleikat. Rio de Janeiro: Livraria do Globo, 1998. (Coleção Biblioteca dos Séculos.)

(5) Para uma ampla discussão dessa temática, cf.: CHARTIER, R. A aventura do livro: do leitor ao navegador. São Paulo: UNESP/Imprensa Oficial do Estado, 1999.

(6) A esse respeito, cf. MARTíN-BARBERO, J. Novos regimes de visualidade e descentramentos culturais. In: VALTER, F. (org.) Batuques, fragmentações e fluxos. Rio de Janeiro: DP\&A, 2000.

(7) SCHIFFERLI, Eduardo Antonio Calliñir. Livro e leitura na era digital. Disponível em: <http://encipecom.metodista.br/mediawiki/images/0/05/GT4-_03-_Livro_e_leitura_-_Eduardo.pdf>. Acesso em: 7 jan. 2012. A definição do texto como evento comunicativo é citada apud MARCUSCHI, Luiz Antônio. A coerência no hipertexto. In: SEMINÁRIO SOBRE HIPERTEXTO, 1. Recife, Universidade Federal de Pernambuco, 2000. Disponível em: <http://bbs.metalink.com.br/ Icoscarelli/Marcuschicoerhtx.doc>.

(8) Idem, ibidem.

(9) RAMAL, Andrea Cecilia. Educação na cibercultura: hipertextualidade, leitura, escrita e aprendizagem. Porto Alegre: Artmed, 2002. Cf. também COSCARELLI, Carla Viana (org.). Novas tecnologias, novos textos, novas formas de pensar. Belo Horizonte: Autêntica, 2002.

(10) JOBIM E SOUZA, Solange; GAMBA JR., Nilton. Novos suportes, antigos temores: tecnologia e confronto de gerações nas práticas de leitura e escrita. Revista Brasileira de Educação, n. 21, set.-dez. 2002. Cf. BAKHTIN. M. Estética de la creación verbal. Madrid: Siglo Vientiuno , 1985.

(11) GEERTZ, C. O impacto do conceito de cultura sobre o conceito de homem. In: A interpretação das culturas. Rio de Janeiro: Guanabara, 1989.

(12) Em um pequeno grande artigo de 1997, Nicolau Sevcenko nos alerta para a percepção convencional da obra de McLuhan como apologia da comunicação de massa, mostrando como, ao contrário, em O meio é a mensagem (The media is the massage, 1967), ele apenas poria em prática o que já anunciara a teoria que sustenta Compreendendo a mídia (1964). Justapondo citações, fotos, publicidade, documentos etnográficos, fotogramas, artes gráficas etc., ele articulava "um fluxo contínuo de fragmentos de diferentes processos comunicativos, numa composição sem sentido seqüencial, cuja conexão só pode ocorrer fora da obra, a partir de um envolvimento perceptivo e intelectual profundo por parte do leitor e coautor". Este "segundo McLuhan", o "anarquista", foi o que "os jovens rebeldes projetaram como o arauto de uma nova sensibilidade, espontânea e solidária, nascida da implosão centrípeta com que as novas tecnologias dissiparam o centralismo autoritário do edifício gutenberguiano". Mais do que nunca, esta inspiração parece hoje revelar sua atualidade. Cf. SEVCENKO, Nicolau. McLuhan assombra o Rei. Folha de São Paulo, Mais, p.6, 23 fev. 1997. É significativo que $\mathrm{o}$ artigo tenha sido republicado em um blog de estudantes de biblioteconomia, Bibliotecários sem Fronteiras, disponível em <http://bsf.org.br/2006/10/03/o-meio-e-a-mensagem/>. 
(13) FLUSSER, V. Ensaio sobre a fotografia. Para uma filosofia da técnica. Lisboa: Relógio d'Água, 1998. Apud JOBIM E SOUZA, S.; GAMBA JR., S., op.cit.

(14) Cf. RAMAL, A. C., op. cit. Apud SCHIFFERLI, E.A, op. cit.

(15) JOBIM E SOUZA, S.; GAMBA JR., N., op. cit.

\section{Referências bibliográficas}

BAKHTIN. M. Estética de la creación verbal. Madrid: Siglo Vientiuno , 1985.

CHARTIER, R. A aventura do livro: do leitor ao navegador. São Paulo: UNESP/Imprensa Oficial do Estado, 1999.

COSCARELLI, Carla Viana (org.). Novas tecnologias, novos textos, novas formas de pensar. Belo Horizonte: Autêntica, 2002.

GEERTZ, C. O impacto do conceito de cultura sobre o conceito de homem. In: A interpretação das culturas. Rio de Janeiro: Guanabara, 1989.

1JOBIM E SOUZA, Solange; GAMBA JR., Nilton. Novos suportes, antigos temores: tecnologia e confronto de gerações nas práticas de leitura e escrita. Revista Brasileira de Educação, n. 21, set.-dez. 2002.

LE GOFF, J. História e memória. 4.ed. Campinas: UNICAMP, 1996.

MARCUSCHI, Luiz Antônio. A coerência no hipertexto. In: SEMINÁRIO SOBRE HIPERTEXTO, 1. Recife, Universidade Federal de Pernambuco, 2000.

MARTÍN-BARBERO, J. Novos regimes de visualidade e descentramentos culturais. In: VALTER, F. (org.) Batuques, fragmentações e fluxos. Rio de Janeiro: DP\&A, 2000.

PLATÃO. Diálogos. Mênon. Banquete. Fedro. Rio de Janeiro: Livraria do Globo, 1998. (Coleção Biblioteca dos Séculos.)

QUEIROZ, Rita de C. R. A informação escrita: do manuscrito ao texto virtual. In: Informação, conhecimento e sociedade digital. VI CINFORM - ENCONTRO NACIONAL DE CIÊNCIAS DA INFORMAÇÃO. Salvador, 14-17 jun. 2005. Disponível em: < http://www.cinform.ufba.br/vi_anais/docs/RitaQueiroz.pdf>. Acesso em: 7 jan. 2012.

RAMAL, Andrea Cecilia. Educação na cibercultura: hipertextualidade, leitura, escrita e aprendizagem. Porto Alegre: Artmed, 2002. 
SCHIFFERLI, Eduardo Antonio Calliñir. Livro e leitura na era digital. Disponível em:

<http://encipecom.metodista.br/mediawiki/images/0/05/GT4-_03__Livro_e_leitura_-_Eduardo.pdf>. Acesso em: 7 jan. 2012.

SEVCENKO, Nicolau. McLuhan assombra o Rei. Folha de São Paulo, Mais, p.6, 23 fev. 1997.

UNESCO. História geral da África I: metodologia e pré-história da África. Brasília: UNESCO, Secad/MEC, UFSCar, 2010. v.1 (Coleção História Geral da África) 